Original Article

\title{
PREPARATION OF ASCORBIC ACID AND CHOLECALCIFEROL MICROSPONGES FOR TOPICAL APPLICATION
}

\author{
RABIA ZIA ${ }^{1 *}$, AKMAL NAZIR², MUHAMMAD KASHIF IQBAL KHAN², ABID ASLAM MAAN² ${ }^{2}$, AYESHA RASHID ${ }^{1}$ \\ ${ }^{1}$ School of Pharmaceutical Sciences, the University of Faisalabad, ${ }^{2}$ Department of Food Engineering, University of Agriculture, Faisalabad, \\ Pakistan \\ Email: rabiapharmacist@yahoo.com
}

Received: 06 Feb 2017 Revised and Accepted: 31 Aug 2017

\begin{abstract}
Objective: Apart from having various physiological functions in the body, ascorbic acid (vitamin $\mathrm{C}$ ) and cholecalciferol (vitamin $\mathrm{D}_{3}$ ) also have a key role in skin protection. However, their bioavailability is quite limited in the skin, and therefore, many cosmetic products are supplemented with these vitamins, which are usually associated with stability issues. To avoid these issues, here we report on the preparation of microsponges of these vitamins for topical application.

Methods: The microsponges were prepared through various emulsification-solvent evaporation methods involving single (0/0, $0 / \mathrm{W})$ or double (W/O/O, W/O/W, S/O/W) emulsion. The organic internal phase was consisted of Eudragit ${ }^{\circledR}$ RS 100 polymer dissolved in an organic solvent such as acetone or dichloromethane, at a constant polymer to drug ratio of 2:1. The prepared microsponges were characterized for their entrapment
\end{abstract} efficiency, droplet size and uniformity, core to wall interaction, and surface morphology.

Results: It was found that the $\mathrm{W} / 0 / \mathrm{W}$ and $\mathrm{S} / 0 / \mathrm{W}$ are suitable methods for the preparation of vitamin $\mathrm{C}$ microsponges and $0 / \mathrm{W}$ is a suitable method for the preparation of vitamin $\mathrm{D}_{3}$ microsponges; ensuring an encapsulation efficiency of around $56-59 \%$ and $93 \%$, respectively. The average diameter of vitamin $\mathrm{C}$ and $\mathrm{D}_{3}$ microsponges was typically around 56-68 $\mu \mathrm{m}$ and $48 \mu \mathrm{m}$, respectively.

Conclusion: It is possible to encapsulate both water and oil soluble vitamins in a microsponge system at an appreciable entrapment efficiency. The findings of the present study are expected to play a vital role in the development of cosmeceuticals.

Keywords: Microsponges, Cosmetics, Controlled release, Ascorbic acid, Cholecalciferol

(C) 2017 The Authors. Published by Innovare Academic Sciences Pvt Ltd. This is an open-access article under the CC BY license (http://creativecommons.org/licenses/by/4.0/) DOI: http://dx.doi.org/10.22159/ijpps.2017v9i10.17525

\section{INTRODUCTION}

Cosmetics are the products that improve beautify or alter the external appearance. With the advancement in research, pharmaceutical and cosmetic industry began to work together to develop novel formulations for topical use. This resulted in the development of cosmeceuticals, the products containing biologically active ingredients or drugs in order to satisfy the need of beauty and health [1]. There are several cosmeceuticals available in the market intended to perform different functions such as anti-ageing, antiwrinkling, whitening, nail and hair care, etc.

Ascorbic acid, commonly known as vitamin C (a water-soluble vitamin), is present as D-ascorbic acid or L-ascorbic acid; however only L-ascorbic acid (LAA) is biologically active. It is a very important antioxidant occurring in nature and possesses several uses when taken orally. However, its limited absorption in the gut results in low bioavailability in the skin [2]. This is the reason that topical application of vitamin $C$ is very much preferred in the clinical practice of dermatology [3]. One of the important functions of topical vitamin $C$ is to protect the skin from reactive oxygen species (ROS) resulting from exposure of skin to ultraviolet (UV) rays. Therefore, to provide optimum photo-protection to skin an adequate quantity of vitamin $\mathrm{C}$ is continuously required. Other functions of vitamin $\mathrm{C}$ include collagen synthesis, lipid-peroxidation, and depigmentation, wound-healing and anti-inflammation [2-4]. A wide variety of products containing vitamin $\mathrm{C}$ for topical application are available including creams, lotions, gels, transdermal patches, etc. However, vitamin $C$ is highly unstable in the presence of air and light and readily oxidizes to dehydroascorbic acid (DHAA) imparting a yellow color to the dosage form. The stability can be improved by lowering $\mathrm{pH}$ of the product $(\mathrm{pH}<3.5)$ or through using vitamin $\mathrm{C}$ derivatives (e. g., ascorbyl 6 palmitate, ascorbic acid sulfate and magnesium ascorbyl phosphate). However, the derivatives do not deliver sufficient quantity to the dermis due to their limited conversion to an active form of vitamin C. Apart from ascorbic acid, cholecalciferol or vitamin $\mathrm{D}_{3}$ (a fat-soluble vitamin) has also been approved for topical use because of its beneficial effects for skin. It is an effective agent in treating certain skin conditions like psoriasis, acne, and dermatitis [5]. Topical ointments have been used in treating psoriasis, a condition in which hyperproliferation of keratinocytes occur. Several studies have shown that calcitriol (also a form of vitamin $\left.D_{3}\right)$ in the ointment $(3 \mu \mathrm{g} / \mathrm{g})$ is safe and very effective in plaque-type psoriasis [6].

The stability and prolonged topical release of these vitamins can be ensured through encapsulation into proper delivery systems. Microsponges are porous microspheres that are made of synthetic polymers, having particle size typically around 5-300 $\mu \mathrm{m}$. These are a highly-preferred dosage form for the topical delivery of drugs because they are associated with least side effects as compared to other dosage forms like microspheres, liposomes, etc. The microspheres, when formulated for topical delivery, are not capable of controlling the release rates of the drug because as soon as the polymeric wall is ruptured all the contents are expelled. The liposomes are difficult to formulate and have stability issues. The microsponges possess many properties that make them suitable for topical drug delivery especially for use in cosmetics. They possess the ability to absorb extra secretion and oil from the skin up to 6 times of their weight because of their porous nature thus preventing greasiness and stickiness associated with conventional dosage forms like ointments, gels, etc. $[7,8]$. One other problem associated with conventional dosage forms is that they provide the active agent at once to skin that may result in overmedication, irritation or rashes on the skin. Whereas, microsponges is a dosage form that has a maximum control on release rates and so can provide a controlled delivery of drug for a longer period of time while maintaining efficacy [9]. Microsponges are also extremely small, microscopic and spherical particles that remain in nooks and crannies of the skin releasing drug very slowly but are large enough and do not absorb in 
the skin. This gives them an extra advantage of being safe for topical use. The drugs that have been explored in microsponge delivery system are ibuprofen, fluconazole, benzyl peroxide, ketoprofen, paracetamol, dicyclomine, flurbiprofen, ketoconazole and retinol [10].

Different types of polymers have been employed for the preparation of microsponges. In the present study, Eudragit ${ }^{\circledR}$ RS 100 was used to form a porous cage for encapsulating vitamin $\mathrm{C}$ and $\mathrm{D}_{3}$. Eudragit ${ }^{\circledR} \mathrm{RS}$ 100 is a copolymer of methyl methacrylate and ethyl acrylate. It also possesses quaternary ammonium groups as salt that makes the polymer permeable and suitable for microsponge preparation. In this study, the microsponges were made through different types of emulsions and the results were compared for a number of parameters.

\section{MATERIALS AND METHODS}

\section{Chemicals}

Eudragit ${ }^{\circledR}$ RS 100 (a gift from Evonik, Pakistan) was used as a polymer for the preparation of microsponges. Vitamin C (ascorbic acid, the molecular weight of $176.13 \mathrm{~g} / \mathrm{mol}$ ) and vitamin $\mathrm{D}_{3}$ (cholecalciferol, the molecular weight of $384.64 \mathrm{~g} / \mathrm{mol}$ ) were purchased from Adisseo, France. Dichloromethane (DCM) or methylene chloride was purchased from EYER ${ }^{\circledR}$, China. Polyvinyl alcohol (molecular weight $72000 \mathrm{~g} / \mathrm{mol}$ ) was purchased from AppliChem, Germany. Ethanol, acetone and acetonitrile were purchased from Merck, Germany.

Magnesium stearate and span 80 were purchased from SigmaAldrich, USA. All the chemicals were of the highest grade available and were used without further purification. Distilled water was used for the preparation of solutions.

\section{Preparation of microsponge}

The microsponges were prepared by different solvent-evaporation methods including either single $(0 / 0,0 / W)$ or double emulsion (W/0/0, W/O/W, S/0/W) techniques [11-15]. The organic internal phase consisted of the certain amount of Eudragit ${ }^{\circledR}$ RS 100 polymer dissolved in organic solvent (acetone or dichloromethane). The detail of each microsponge formulation prepared in this study is shown in table 1. In all the cases, the drug to polymer ratio was 1:2. The evaporation phase was consisted of mixing at $1000 \mathrm{rpm}$ for $3 \mathrm{~h}$ at room temperature. The formed microsponges were filtered, washed with distilled water or $\mathrm{n}$-hexane (for 2 to 3 times), and then dried at room temperature.

Determination of production yield, actual drug content and entrapment efficiency

The production yield, actual drug content and entrapment efficiency were calculated as described by Abdelmalak and ElMenshawe [16]. The production yield was determined by accurately calculating the initial weight of the raw materials and the weight of the obtained microsponge particles. The samples of vitamin C loaded microsponge $(20 \mathrm{mg}$ ) was dissolved in $10 \mathrm{ml}$ phosphate buffer ( $\mathrm{pH}$ 5.5) under sonication (E60H, ELMA, Germany) for $20 \mathrm{~min}$ at $25^{\circ} \mathrm{C}$.

The samples were filtered using $0.45 \mu \mathrm{m}$ membrane filter and analyzed for ascorbic acid content with a spectrophotometer (3000 Series, Cecil, UK) at $265 \mathrm{~nm}$. On the other hand, the amount of vitamin $\mathrm{D}_{3}$ per unit weight of microparticle was determined by dissolving 10 $\mathrm{mg}$ of microsponges in $1 \mathrm{ml}$ of dichloromethane, and the vitamin concentration was determined by spectrophotometric analysis at 242 $\mathrm{nm}$ [17]. The actual drug content and encapsulation efficiency were calculated as:

$$
\begin{aligned}
& \text { Actual drug content }(\%)=\left(\frac{\mathrm{M}_{\mathrm{act}}}{\mathrm{M}_{\mathrm{ms}}}\right) \times 100 \ldots \ldots \ldots(1) \\
& \text { Entrapment efficiency }(\%)=\left(\frac{\mathrm{M}_{\mathrm{act}}}{\mathrm{M}_{\mathrm{the}}}\right) \times 100 \ldots \ldots \ldots(2)
\end{aligned}
$$

Where $\mathrm{M}_{\mathrm{act}}$ is the actual drug content in the weighed quantity of the microsponge, $\mathrm{M}_{\mathrm{ms}}$ is the weighed quantity of powder of microsponge, and $\mathrm{M}_{\text {the }}$ is the theoretical amount of ascorbic acid in microsponge calculated from the quantity added during preparation.

\begin{tabular}{|c|c|c|c|}
\hline $\begin{array}{l}\text { Formul } \\
\text { ation }\end{array}$ & Drug & Method & Description \\
\hline$\overline{F_{1}}$ & $\begin{array}{l}\text { Ascorbic } \\
\text { acid }\end{array}$ & $\mathrm{O}_{1} / \mathrm{O}_{2}$ & $\begin{array}{l}\mathrm{O}_{1}=\text { polymer }(1 \mathrm{~g})+\text { acetone }(5 \mathrm{ml})+\mathrm{mg} \text {. stearate }(3 \mathrm{w} / \mathrm{v} \% \text { of acetone })+\operatorname{drug}(0.5 \mathrm{~g}) ; \mathrm{O}_{2}=\text { liquid paraffin }(100 \mathrm{ml}) \\
\text { Procedure: } \mathrm{O}_{1} \text { phase was sonicated for } 3 \mathrm{~min} \text { and then added into } \mathrm{O}_{2} \text { phase while stirring } \rightarrow \text { Solvent evaporation while stirring } \rightarrow \text { Separation } \rightarrow \\
\text { Washing with n-hexane }\end{array}$ \\
\hline $\mathrm{F}_{2}$ & $\begin{array}{l}\text { Ascorbic } \\
\text { acid }\end{array}$ & $\begin{array}{l}\mathrm{W} / \mathrm{O}_{1} / 0 \\
2\end{array}$ & $\begin{array}{l}\mathrm{W}=\text { water }(0.5 \mathrm{ml})+\operatorname{drug}(0.5 \mathrm{~g}) ; \mathrm{O}_{1}=\text { polymer }(1 \mathrm{~g})+\text { acetone }(5 \mathrm{ml})+\mathrm{mg} \text {. stearate }(3 \mathrm{w} / \mathrm{v} \% \text { of acetone }) ; \mathrm{O}_{2}=\text { liquid paraffin }(100 \mathrm{ml}) \\
\text { Procedure: } \mathrm{W} \text { phase was added to } \mathrm{O}_{1} \text { phase and then resulting } \mathrm{W} / \mathrm{O}_{1} \text { emulsion was sonicated for } 3 \mathrm{~min} \text {, and then added to } \mathrm{O}_{2} \text { phase while } \\
\text { stirring } \rightarrow \text { Solvent evaporation while stirring } \rightarrow \text { Separation } \rightarrow \text { Washing with } \mathrm{n} \text {-hexane }\end{array}$ \\
\hline $\mathrm{F}_{3}$ & $\begin{array}{l}\text { Ascorbic } \\
\text { acid }\end{array}$ & $\begin{array}{l}\mathrm{W} / \mathrm{O}_{1} / \mathrm{O} \\
2\end{array}$ & $\begin{array}{l}\mathrm{W}=\text { water }(0.5 \mathrm{ml})+\mathrm{drug}(0.5 \mathrm{~g}) ; \mathrm{O}_{1}=\text { polymer }(1 \mathrm{~g})+\text { acetone }(5 \mathrm{ml})+\mathrm{mg} . \text { stearate }(3 \mathrm{w} / \mathrm{v} \% \text { of acetone }) ; \mathrm{O}_{2}=\text { liquid paraffin }(100 \mathrm{ml})+\operatorname{span} 80 \\
(0.1 \%) \\
\text { Procedure: Same as } \mathrm{F}_{2}\end{array}$ \\
\hline $\mathrm{F}_{4}$ & $\begin{array}{l}\text { Ascorbic } \\
\text { acid }\end{array}$ & $\begin{array}{l}\mathrm{W}_{1} / \mathrm{O} / \mathrm{W} \\
2\end{array}$ & $\begin{array}{l}\mathrm{W}_{1}=\text { water }(2 \mathrm{ml})+\mathrm{drug}(0.5 \mathrm{~g}) ; \mathrm{O}=\text { polymer }(1 \mathrm{~g})+\mathrm{DCM}(10 \mathrm{ml}) ; \mathrm{W}_{2}=\text { Water+PVA }(0.5 \%) \\
\text { Procedure: } \mathrm{W}_{1} / 0 \text { emulsion was prepared by homogenizer and then added to } \mathrm{W}_{2} \text { phase while stirring } \rightarrow \text { Solvent evaporation while stirring } \rightarrow \\
\text { Separation } \rightarrow \text { Washing with water }\end{array}$ \\
\hline$F_{5}$ & $\begin{array}{l}\text { Ascorbic } \\
\text { acid }\end{array}$ & $\begin{array}{l}\mathrm{W}_{1} / \mathrm{O} / \mathrm{W} \\
2\end{array}$ & $\begin{array}{l}\mathrm{W}_{1}=\text { water }(2 \mathrm{ml})+\operatorname{drug}(0.5 \mathrm{~g}) ; 0=\text { polymer }(1 \mathrm{~g})+\mathrm{DCM}(10 \mathrm{ml}) ; \mathrm{W}_{2}=\text { Water+PVA }(0.75 \%) \\
\text { Procedure: Same as } \mathrm{F}_{4}\end{array}$ \\
\hline $\mathrm{F}_{6}$ & $\begin{array}{l}\text { Ascorbic } \\
\text { acid }\end{array}$ & $\mathrm{W}_{1} / \mathrm{O} / \mathrm{W}$ & $\begin{array}{l}\mathrm{W}_{1}=\text { water }(2 \mathrm{ml})+\operatorname{drug}(0.5 \mathrm{~g}) ; 0=\text { polymer }(1 \mathrm{~g})+\mathrm{DCM}(10 \mathrm{ml})+\operatorname{span} 80(0.1 \%) ; \mathrm{W}_{2}=\text { Water+PVA }(0.5 \%) \\
\text { Procedure: Same as } \mathrm{F}_{4}\end{array}$ \\
\hline $\mathrm{F}_{7}$ & $\begin{array}{l}\text { Ascorbic } \\
\text { acid }\end{array}$ & $\mathrm{S} / \mathrm{O} / \mathrm{W}$ & $\begin{array}{l}\mathrm{S}=\text { finely grounded drug }(0.5 \mathrm{~g}) ; 0=\text { polymer }(1 \mathrm{~g})+\mathrm{DCM}(10 \mathrm{ml})+\operatorname{span} 80(0.1 \%) ; \mathrm{W}=\mathrm{Water}+\mathrm{PVA}(0.75 \%) \\
\text { Procedure: The grounded drug was directly added to } \mathrm{O} \text { phase, which was then added to } \mathrm{W} \text { phase while stirring } \rightarrow \text { Solvent evaporation while } \\
\text { stirring } \rightarrow \text { Separation } \rightarrow \text { Washing with water }\end{array}$ \\
\hline $\mathrm{F}_{8}$ & $\begin{array}{l}\text { Cholecalc } \\
\text { iferol }\end{array}$ & $0 / \mathrm{W}$ & $\begin{array}{l}0=\text { Cholecalciferol }(0.5 \mathrm{~g})+\text { polymer }(1 \mathrm{~g})+\mathrm{DCM}(10 \mathrm{ml}) ; \mathrm{W}=\text { Water+PVA }(0.5 \%) \\
\text { Procedure: } \mathrm{O} \text { phase was added to } \mathrm{W} \text { phase while stirring } \rightarrow \text { Solvent evaporation while stirring } \rightarrow \text { Separation } \rightarrow \text { Washing with water }\end{array}$ \\
\hline
\end{tabular}

Table 1: Microsponge formulations of ascorbic acid and cholecalciferol

\section{Determination of size and uniformity of microspheres}

The prepared microspheres were analyzed for size and uniformity by using an optical microscope (CAM2800-XP 3.0, Micros, Austria).

From each experiment, the size of approximately 150-200 microspheres were analyzed through image analysis, and then mean particle size was calculated. The uniformity of the microsponge was expressed in terms of coefficient of variance (CV) calculated as:
Coefficient of variation $=\left(\frac{\text { Standard deviation of particle size }}{\text { Mean particle size }}\right) \times 100$.....(3)

Characterization of microsponge using Fourier-transform infrared (FTIR) spectrophotometry

FTIR spectra of the pure ascorbic acid and pure cholecalciferol, and their respective microsponge formulation were recorded on FT-IR spectrophotometer (VERTEX 70, Bruker, Germany). The infrared absorbance was acquired from the wavenumber of $500-4000 \mathrm{~cm}^{-1}$ with a resolution of $4 \mathrm{~cm}^{-1}$. 
Surface topography and morphology of microsponge formulations using scanning electron microscope (SEM)

The surface topography and morphology of microsponges were analyzed through scanning electron microscope (Quanta 250, FEI, USA). The microsponge samples (without coating) were mounted on a sample holder with a help of a double-sided adhesive tape. The samples were transferred to the microscope where they were analyzed at $10 \mathrm{kV}$ under vacuum conditions. The images were recorded at different suitable magnifications.

\section{Statistical analysis}

The data obtained from each parameter was subjected to statistical analysis to determine the mean values along with standard deviation $( \pm \mathrm{SD})$. The analysis of variance was carried out at $95 \%$ confidence limit $(\mathrm{P}<0.05)$ using Statistix 8 software.

\section{RESULTS AND DISCUSSION}

\section{Preparation of microsponges}

The microsponges were prepared by a quasi-emulsion solvent diffusion method by a two-step process (i.e., emulsification followed by solvent evaporation), which is also regarded as a topdown approach. This method is quite simple and can give reproducible results [18]. In this study, different types of emulsions were tested as described in detail in table 1 . To our knowledge, no systematic study has been reported so far for the preparation of vitamin $\mathrm{C}$ microsponges through emulsificationsolvent evaporation method; and therefore, different combinations of both single and double emulsions were analyzed. It was observed that the type of emulsion used had a significant effect on the preparation of the microsponges (fig. 1). The main objective of using $0 / 0$ method $\left(F_{1}\right)$ was to achieve maximum encapsulation efficiency of vitamin $\mathrm{C}$; however, this formulation did not result in individual microsponges, rather it formed clusters of polymer and drug. The visual observation showed that the vitamin $C$ was not totally soluble in the internal organic phase. To cope with solubility issue, a small quantity of water $(0.5 \mathrm{ml})$ was added into the internal phase resulting in the formation of $\mathrm{W} / 0 / 0$ emulsion $\left(\mathrm{F}_{2}\right)$. However, similar to the microsponges that were prepared using $0 / 0$ method, the aggregation took place.

In another formulation $\left(\mathrm{F}_{3}\right)$, span 80 (an oil-soluble surfactant) was added in the external 0 phase at a concentration of $0.1 \%$. The microscopic observation revealed that there were no aggregates of the internal phase; however, the addition of span 80 significantly impaired the formation of microsponges. In this formulation, few microsponges were present and most of the polymer existed in the form of irregularly shaped debris without encapsulating the drug. These results showed that although the addition of span 80

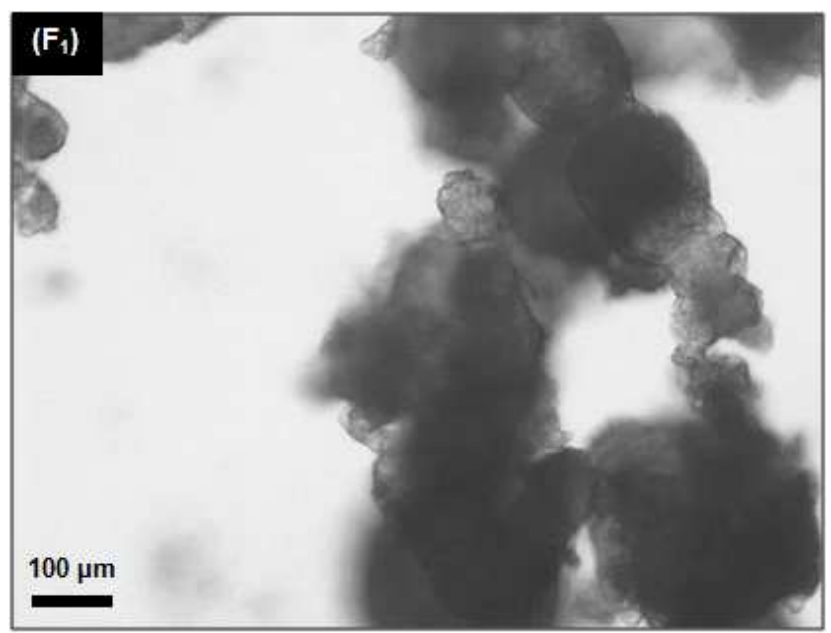

significantly reduced the aggregate formation but still there were very few signs of microsponge formation. Here it is important to know that span 80 is a non-ionic oil-soluble surfactant and provides droplet stabilization through steric hindrance [19]. It caused a great extent of repulsion between internal droplets so the emulsion was broken into small irregular fragments. This was also previously reported by Rizkalla et al. [15] where the addition of span 80 resulted in nano-sized microsponges that were not acceptable for topical use.

Contrary to $0 / 0$ or $\mathrm{W} / 0 / 0$, the $\mathrm{W} / 0 / \mathrm{W}$ emulsion resulted in the successful formation of spherical microsponges of varying sizes (fig. 1). As polyvinyl alcohol (PVA) acts as a stabilizer for the dispersed phase, increasing the PVA concentration had a positive effect on the integrity of the microsponges, i.e., the surface of the microsponges was more uniform and less porous $\left(\mathrm{F}_{4} \mathrm{vs}_{\mathrm{F}} \mathrm{F}_{5}\right)$. Similar results were also shown in studies performed by various researchers [20-22]. Furthermore, in another preparation, span 80 was added into the oil phase at a concentration of $0.1 \%\left(\mathrm{~F}_{6}\right)$. The microscopic observation showed that the addition of span 80 had a negative impact on the encapsulation of vitamin C. The addition of span 80 resulted in small and irregular particles or fragments of the polymer. Hence, in both formulations, i.e., $F_{3}$ and $F_{6}$, the addition of span 80 impaired the microsponge formation that is in line with results reported by Rizkalla et al. [15].

Although, microparticles are most commonly prepared by W/O/W emulsion; however, in literature few studies have been reported relating to pharmaceutical research in which $\mathrm{S} / \mathrm{O} / \mathrm{W}$ emulsion was used for the encapsulation of proteins and hormones to ensure their high stability [23]. Moreover, this method is usually applied to ensure high encapsulation efficiency and loading capacity [24]. In another formulation $\left(\mathrm{F}_{7}\right)$, microsponges were prepared through $\mathrm{S} / \mathrm{O} / \mathrm{W}$ method that is preferably used for encapsulating small sized powdered drugs that can easily dispersed in the organic internal phase.

In this method, vitamin $\mathrm{C}$ powder was directly added into solvent and polymer mixture resulting in $\mathrm{S} / 0$ dispersion. This primary S/O was then dispersed into $0.75 \%$ aqueous solution of PVA. A number of spherical microsponges of varying sizes were observed under the optical microscope. Apparently, there was no significant difference between the microsponges prepared through $\mathrm{S} / \mathrm{O} / \mathrm{W}$ and $\mathrm{W} / 0 / \mathrm{W}$ methods.

As vitamin $D_{3}$ is an oil soluble vitamin, its encapsulation is not as problematic as that of vitamin C. Therefore, only $\mathrm{O} / \mathrm{W}$ method was tested for the preparation of vitamin $\mathrm{D}_{3}$ microsponges $\left(\mathrm{F}_{8}\right)$ that successfully resulted in fine microsponge particles. In the following sections, the microsponge particles prepared through different formations were characterized and compared with each other.

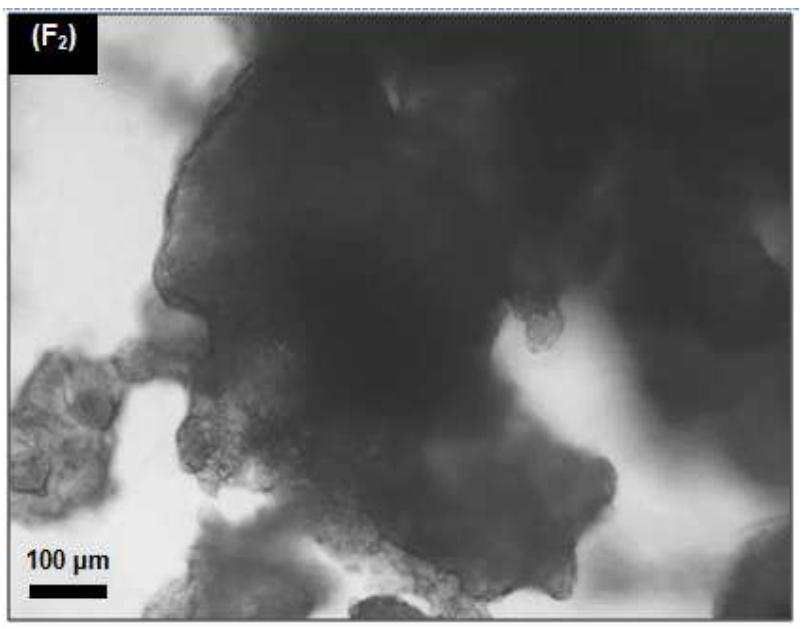



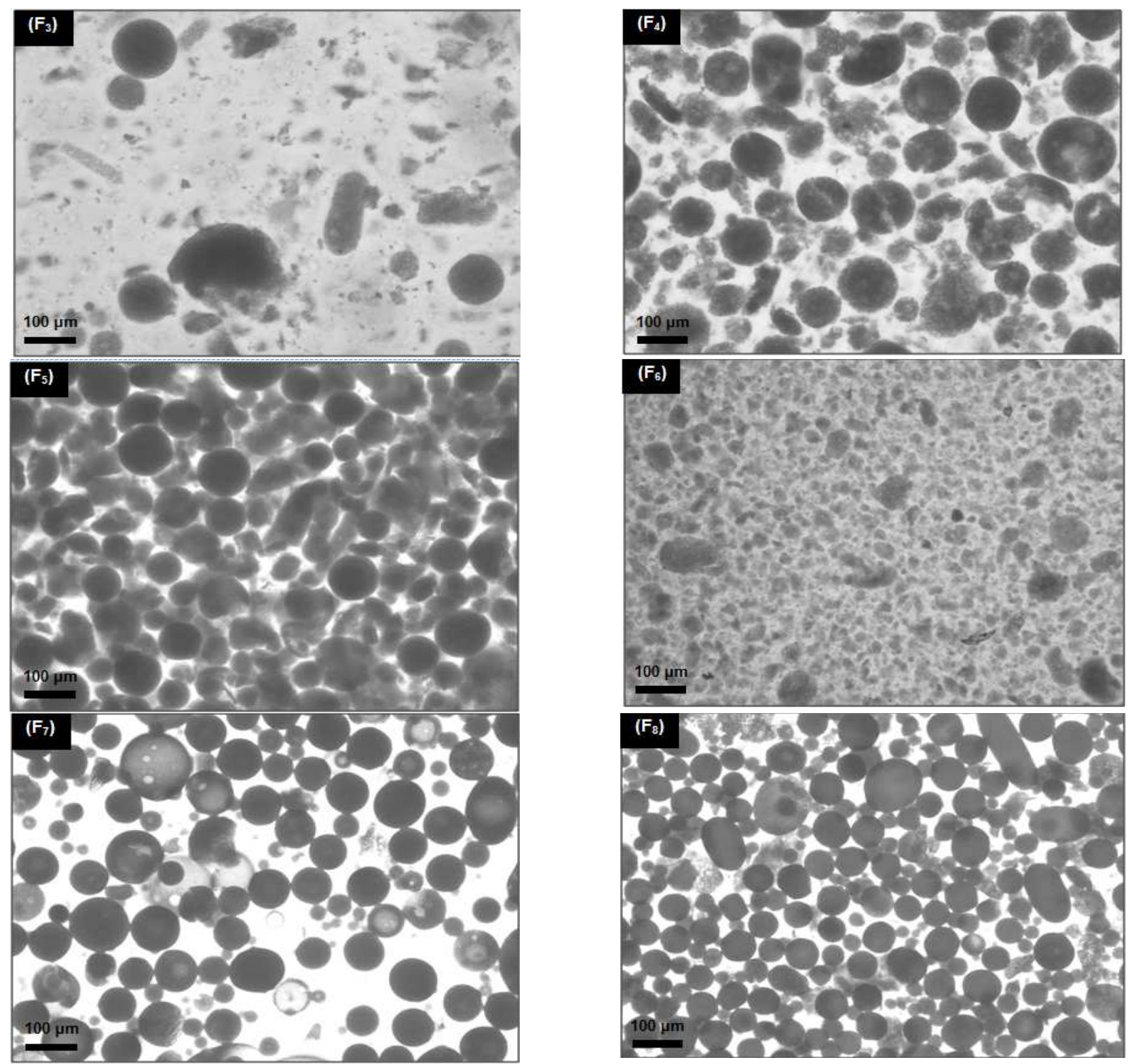

Fig. 1: Images of different formulations of microsponges taken with an optical microscope at 10X (See table 1 for description of formulations)

\section{Size and size distribution of various microsponge formulations}

The size and size distribution is an important parameter that may affect the drug loading capacity as well as the drug release [24]. The formulations that resulted in successful microsponge preparation (i.e., $F_{4}, F_{5}, F_{7}$ and $F_{8}$ ) were further compared for their size (average diameter) and size distribution (coefficient of variation) as determined through image analysis (fig. 2). There was a significant difference for size and size distribution of various microsponge formulations $(p<0.05)$. The average diameter of vitamin $C$ and $D_{3}$ microsponges was typically around 56-68 $\mu \mathrm{m}$ (depending upon the formulation type) and $48 \mu \mathrm{m}$, respectively. The size of microsponges that has been reported in the literature ranges between 5-300 $\mu \mathrm{m}$ [25]. Hence, the size of microsponges that was obtained in this study was in accordance to the already reported size range and well suited for the topical application.

PVA is a water-soluble non-ionic surfactant that is widely used as a stabilizer in the preparation of particles by avoiding the droplet coalescence during emulsification and subsequent solidification process $[13,14]$. It is evident from the results that increasing PVA concentration $\left(\mathrm{F}_{4} \mathrm{vs} \mathrm{F}_{5}\right)$ did not significantly affected the mean microsponge size; however, there was a significant decrease in the size distribution of the microsponges. Earlier, Qi et al. [14] also reported an similar findings who prepared exenatide-loaded poly(d,-lactic-co-glycolic acid) (PLGA) microspheres through premix membrane emulsification. According to their finding, a large size distribution at low PVA concentration is due to broken particles in the absence of proper stabilization. Moreover, droplet coalescence may be another possible destabilizing mechanism responsible for the presence of a large particle. Here it is important to mention that too high PVA concentration can also have a negative impact on the particle size as reported by Nokhodchi et al. [13] who obtained bigger microparticles when the concentration of PVA was higher. They justified that the increase in size can be attributed to an increase in apparent viscosity at increased emulsifier concentrations.

On comparison of microsponges prepared with $\mathrm{W} / \mathrm{O} / \mathrm{W}\left(\mathrm{F}_{5}\right)$ and $\mathrm{S} / \mathrm{O} / \mathrm{W}\left(\mathrm{F}_{7}\right)$ methods, it was found that the average diameter was small for microsponges prepared through $\mathrm{S} / \mathrm{O} / \mathrm{W}$. In both formulations, the PVA concentration was constant in the outer water phase. As in case of $\mathrm{S} / \mathrm{O} / \mathrm{W}$ method, there was no inner water phase and the drug as present in particulate form, and therefore, it may not be possible for the drug particles to distribute evenly into different microsponge forming units. This situation also has resulted in a decreased uniformity of the prepared microsponges. The particle 
size in case of $\mathrm{S} / \mathrm{O} / \mathrm{W}$ emulsion is dependent on several factors such as the size of drug particles, the polymer to drug ratio, etc. [26]. Hence, a small microsponge size may be obtained by using a drug of small particle size or through using high polymer to drug ratio.

The average diameter of vitamin $\mathrm{D}_{3}$ microsponges was smaller than all the vitamin C preparations. This was due to single $\mathrm{O} / \mathrm{W}$ emulsion that was used for the preparation of oil soluble vitamin $D_{3}$, which has resulted in the formation of comparatively smaller microsponges. However, the obtained microsponges were more uniform than microsponges prepared through $\mathrm{F}_{4}$ and $\mathrm{F}_{7}$ but a little less uniform as compared to those prepared by $\mathrm{F}_{5}$. The coefficient of variation of vitamin $\mathrm{D}_{3}$ microsponges was $40 \%$, whereas, in case of vitamin $\mathrm{C}$ microsponges prepared through $\mathrm{W} / \mathrm{O} / \mathrm{W}\left(\mathrm{F}_{5}\right)$ the coefficient of variation was $34 \%$. This slight increase in size distribution is related to the presence of a number of small-sized microsponges in the whole population which actually gave a higher coefficient of variation and a comparatively small average diameter of microsponges.

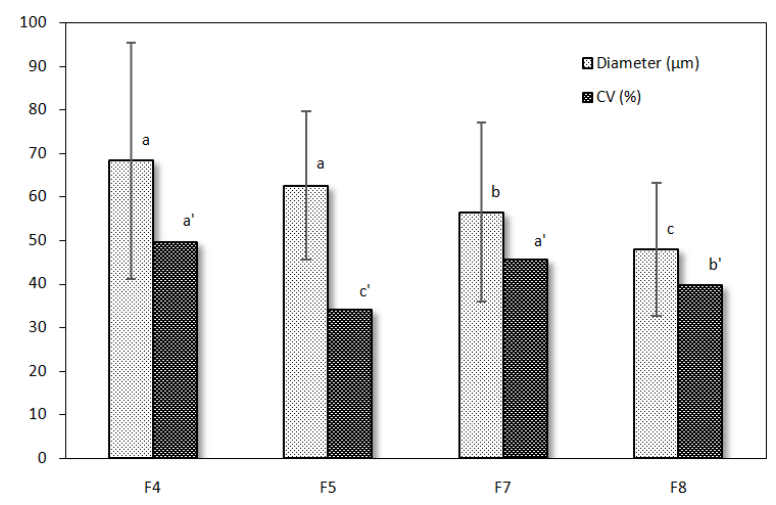

Fig. 2: Comparison of different microsponge formulations for their diameter and coefficient of variance ( $\mathrm{CV}$ ). The values are mean of 150-200 microsponges $\pm S D(p<0.05)$

\section{Production yield, actual drug content and entrapment efficiency}

In this section, the vitamin $\mathrm{C}$ microsponges prepared using $\mathrm{W} / \mathrm{O} / \mathrm{W}$ $\left(\mathrm{F}_{5}\right)$ and $\mathrm{S} / \mathrm{O} / \mathrm{W}\left(\mathrm{F}_{7}\right)$ methods, and vitamin $\mathrm{D}_{3}$ microsponges prepared using $\mathrm{O} / \mathrm{W}\left(\mathrm{F}_{8}\right)$ method are compared for production yield, actual drug content and entrapment efficiency. In these formulations, the rest of parameters were kept constant, i.e., a drug to polymer ratio was $1: 2$, dichloromethane was solvent, and $0.75 \%$ aqueous solution of polyvinyl alcohol (PVA) was external water phase.

The statistical analysis showed that all the microsponge formulations varied significantly $(\mathrm{p}<0.05)$ in terms of their production yield, actual drug content and entrapment efficiency; with vitamin $\mathrm{D}_{3}$ microsponges having higher values for all these parameters (fig. 3). However, there was a non-significant difference between $\mathrm{F}_{5}$ and $\mathrm{F}_{7}$ formulations for vitamin $\mathrm{C}$ microsponges. Among these parameters, the entrapment efficiency is an important parameter that is used to evaluate the success of drug loading in a system. In the present study, the average encapsulation efficiency of vitamin $\mathrm{C}$ and $\mathrm{D}_{3}$ was typically around $56-59 \%$ and $93 \%$, respectively. A wide variation in production yield entrapment efficiency and actual drug content of vitamin $C$ and $D_{3}$ is due to different nature of the two actives. Vitamin $\mathrm{D}_{3}$ being an oil-soluble vitamin is very suitable and conveniently encapsulated by single $\mathrm{O} / \mathrm{W}$ emulsion. A number of hydrophobic drugs were encapsulated successfully by using $\mathrm{O} / \mathrm{W}$ method giving high production yield up to $97 \%$ as also reported by Nokhodchi [13]. However, being the hydrophilic nature of vitamin $\mathrm{C}$, an encapsulation efficiency of around $56-59 \%$ is quite high as an encapsulation of hydrophilic drugs is quite challenging. In a review by Abbas et al. [27], the encapsulation efficiency has been compared for different techniques used for vitamin $\mathrm{C}$ microencapsulation. The reported encapsulation efficiency is between $10-100 \%$. In that respect, an encapsulation efficiency of $\sim 60 \%$ for a porous microsponge particle is quite appreciable.
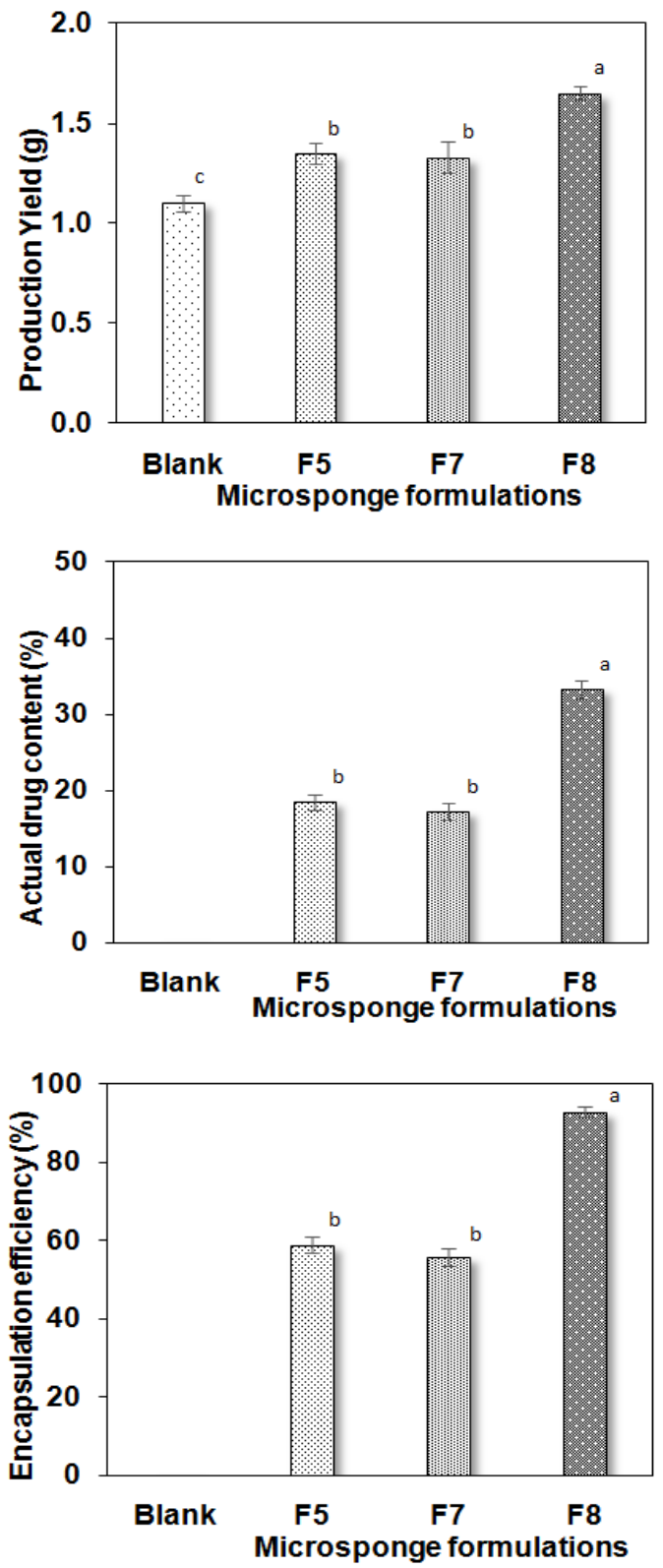

Fig. 3: Production yield, actual drug content and encapsulation efficiency of different microsponge formulations. The values are mean of three independent replicates $\pm S D(p<0.05)$

\section{Characterization of microsponge using fourier-transform infrared spectra (FTIR)}

The core to wall interaction was analyzed through FTIR spectroscopy to identify the interaction between encapsulated vitamin and the polymer of microsponges. The principle of FTIR is based on fact that every organic radical give rise to a characteristic series of bands. Their characteristic frequencies are almost unaffected by other groups present in the same molecule or in neighbouring molecules. So, it provides a useful way to identify drugs. In this study, the FT-IR spectra of the pure ascorbic acid and pure cholecalciferol, and their respective microsponge formulations was recorded on a FT-IR spectrophotometer and the results are shown in fig. 4 and 5. From the literature, it has been found that on infrared absorption spectra of the standard ascorbic acid there are typical absorption peaks of carbon-carbon double bond around $1600-1700 \mathrm{~cm}^{-1}$ and $3000-3100 \mathrm{~cm}^{-1}$, hydroxyl group near the range 
of $1000-1200 \mathrm{~cm}^{-1}$ and $3000-3700 \mathrm{~cm}^{-1}$, and carbonyl group near the range of $1550-1870 \mathrm{~cm}^{-1}$ and $3400-3500 \mathrm{~cm}^{-1}[28,29]$. The absorption peaks of the pure ascorbic acid used in this study were very much in agreement to the values reported in the literature. Moreover, FTIR spectra of the microsponge formulation of ascorbic acid were comprised of the characteristic peeks similar to the pure component. On the other hand, the cholecalciferol is typified by the $\mathrm{CH}_{3}$ asymmetric stretching mode and the $\mathrm{CH}_{2}$ symmetric stretching mode at 2943 and $2875 \mathrm{~cm}^{-1}$, respectively. Two other characteristic peaks are around 1752 and 1162 representing stretching vibrations of $\mathrm{C}=\mathrm{O}$ and C-O-C bonds, respectively [30]. The FTIR spectra of the pure cholecalciferol used in the present study were in accordance to the absorption spectra of the standard cholecalciferol found in the literature. Most importantly, on a comparison of absorption spectra of pure ascorbic acid and cholecalciferol with their respective formulations, it was found that there was no sign of any interaction between the drug and the coating material.

The encapsulated materials were in their pure form as indicated by the presence of same characteristics peeks of the pure and the encapsulated material. These results proved the compatibility of both vitamins with excipient used for microsponge preparation.

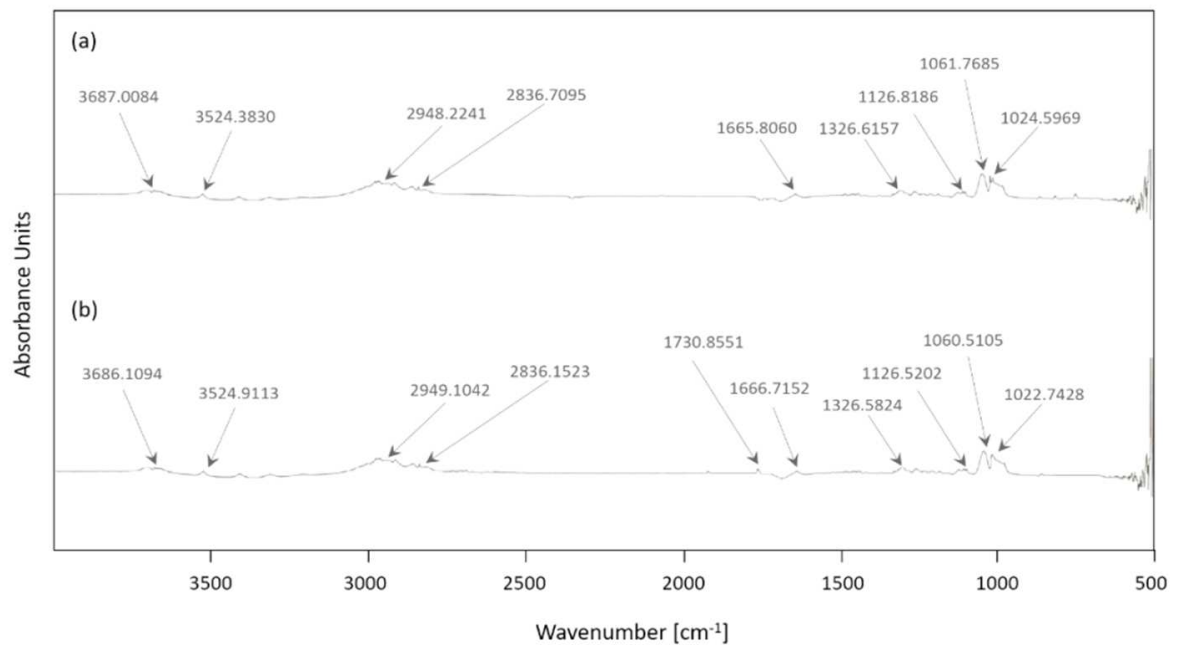

Fig. 4: FTIR spectra of (a) pure and (b) encapsulated ascorbic acid

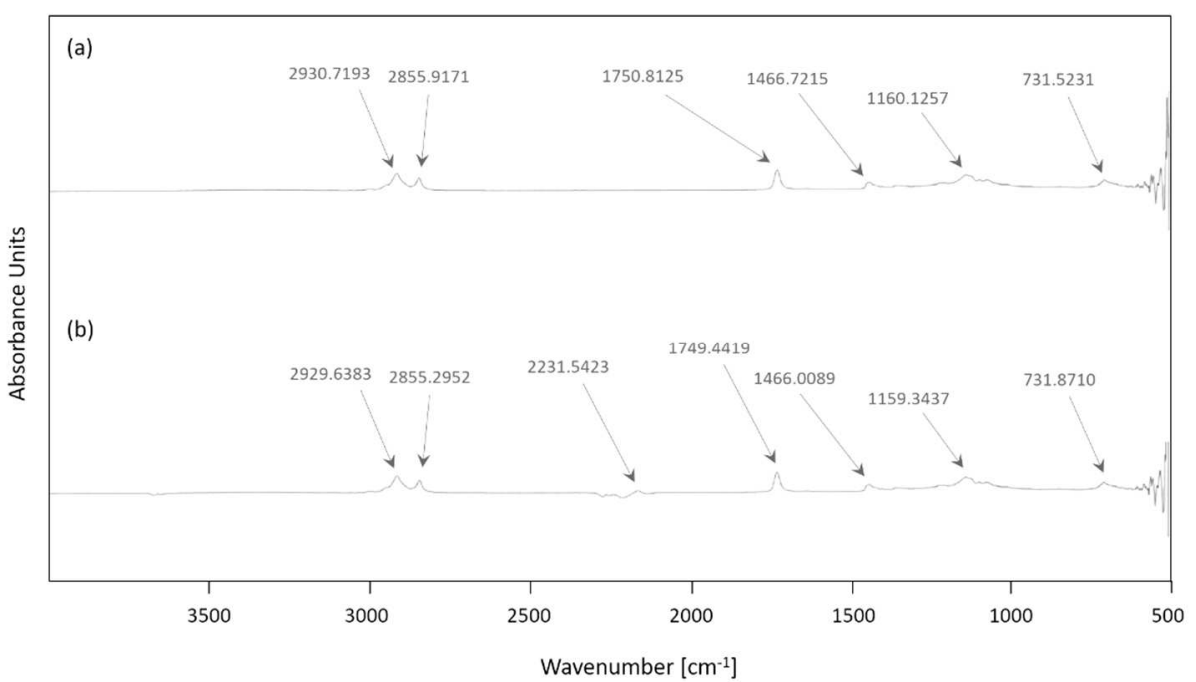

Fig. 5: FTIR spectra of (a) pure and (b) encapsulated cholecalciferol

\section{Study of surface topography and morphology of microsponge} formulations using scanning electron microscope (SEM)

Surface topography and morphology of microsponges were analyzed by using scanning electron microscope. Although images from optical microscope gave some idea about surface morphology but the representative SEM images gave a very clear picture as shown in fig. 6 and 7. The difference in shape, size, and surface morphology of the two type of microsponges, i.e., vitamin C and $D_{3}$ can be clearly observed through SEM analysis. Vitamin C SEM analysis showed that microsponges were a course in appearance, porous, predominantly spherical with few of them having an irregular shape. The pores on the surface of the sponges can also be observed, as these are created by solvent diffusion from the surface of microsponges. Moreover, it can also be observed that the microsponges consist of a stiff shell assembly having a distinct internal spherical cavity. The SEM analysis of vitamin C showed that the surface is very rough and somewhat layered. Some irregular shaped fragments are also seen that are assumed to be of the polymer. On the other hand, vitamin $\mathrm{D}_{3}$ SEM analysis showed that microsponges are more appropriate in terms of their surface morphology and topography. The SEM results indicated that microsponges formed were much spherical in shape, porous, small with a less variation in shape and size, and comparatively smoother. The vitamin $\mathrm{D}_{3}$ microsponges seem to be flexible and porous and predominantly spherical with internal annulled 
spaces. Most of the microsponges appeared as a single entity and unlike those of vitamin $C$ have a least overlapping. The solvent diffusion from the surface of the microsponge particles is regarded as a possible mechanism for the formation of pores [13].

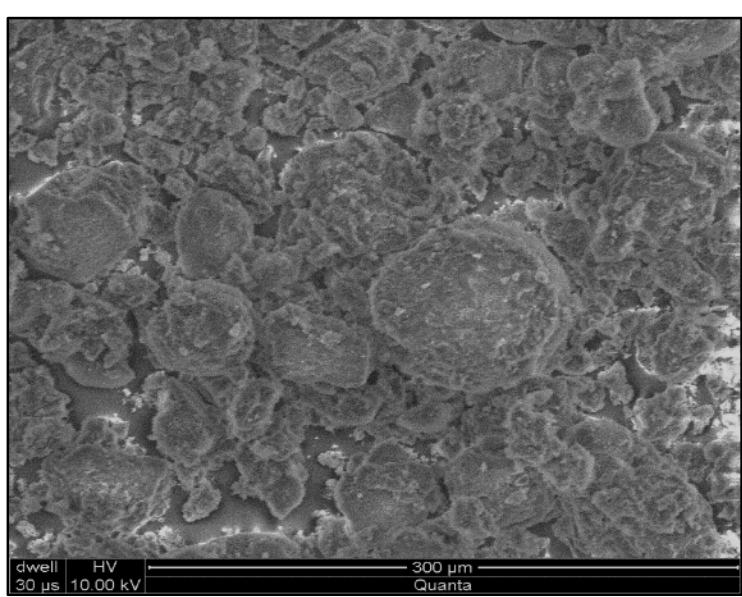

Fig. 6: Scanning electron microscope image of Vitamin C microsponges prepared by $\mathrm{W} / \mathrm{O} / \mathrm{W}\left(\mathrm{F}_{5}\right)$

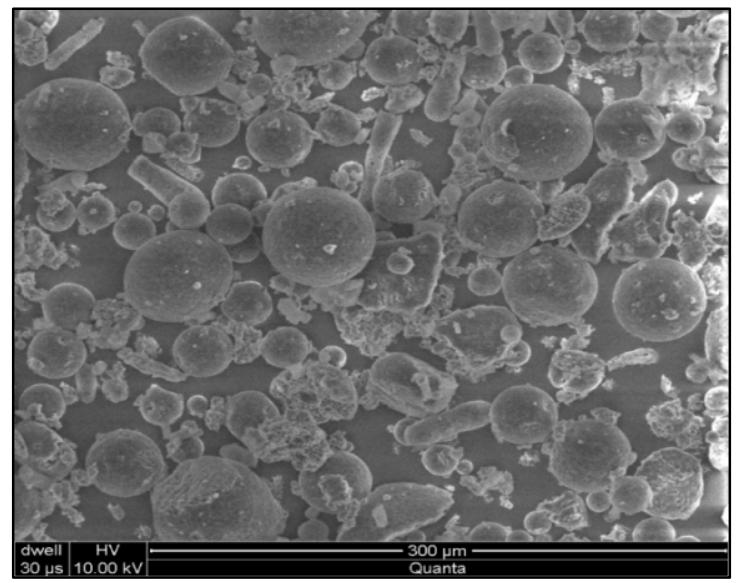

Fig. 7: Scanning electron microscope image of Vitamin $D_{3}$ microsponges prepared by $0 / \mathrm{W}\left(\mathrm{F}_{8}\right)$

\section{AUTHORS CONTRIBUTION}

\begin{tabular}{ll}
\hline Author & Role \\
Rabia Zia, MPhil & $\bullet$ Performed research work \\
& $\bullet$ Manuscript writing \\
& $\bullet$ Correspondence with the journal \\
Akmal Nazir, PhD & $\bullet$ Assisted research work \\
Muhammad Kashif Iqbal & $\bullet$ Manuscript writing \\
Khan, PhD & $\bullet$ Edited and revised the manuscript \\
Abid Aslam Maan, PhD & Edited and revised the manuscript \\
Ayesha Rashid, PhD & $\bullet$ Supervised the research \\
\hline
\end{tabular}

\section{CONCLUSION}

The results of present study affirm that not all the emulsification methods are suitable for the preparation of microsponges. The $\mathrm{W} / \mathrm{O} / \mathrm{W}$ and $\mathrm{S} / \mathrm{O} / \mathrm{W}$ are suitable methods for the preparation of vitamin $\mathrm{C}$ microsponges and $\mathrm{O} / \mathrm{W}$ is the suitable method for the preparation of vitamin D3 microsponges; ensuring an encapsulation efficiency of around $56-59 \%$ and $93 \%$, respectively.
The average diameter of vitamin C and D3 microsponges was typically around 56-68 $\mu \mathrm{m}$ and $48 \mu \mathrm{m}$, respectively; and the size distribution was rather uniform. The FTIR analysis revealed the absence of any interaction between the drug and the coating material. The findings of the present study are expected to play a vital role in the development of cosmeceuticals to effectively encapsulate the biologically active ingredient or drug.

\section{CONFLICT OF INTERESTS}

Declared none

\section{REFERENCES}

1. Gao XH, Zhang L, Wei H, Chen HD. Efficacy and safety of innovative cosmeceuticals. Clin Dermatol 2008;26:367-74.

2. Traikovich SS. Use of topical ascorbic acid and its effects on photodamaged skin topography. Arch Otolaryngol Head Neck Surg 1999;125:1091-8.

3. Matsuda S, Shibayama H, Hisama M, Ohtsuki M, Iwaki M. Inhibitory effects of a novel ascorbic derivative, disodium isostearyl 2-OL-ascorbyl phosphate on melanogenesis. Chem Pharm Bull 2008;56:292-7.

4. Draelos ZD. Skin lightening preparations and the hydroquinone controversy. Dermatol Ther 2007;20:308-13.

5. Polat M, Uzun Ö. Vitamin D in dermatology. OA Dermatol 2014;2:9.

6. Kircik L. Efficacy and safety of topical calcitriol 3 microg/g ointment, a new topical therapy for chronic plaque psoriasis. J Drugs Dermatol 2009;8(Suppl 8):9-16.

7. Vyas SP, Khar RK. Targeted and controlled drug delivery: novel carrier systems. CBS publishers and distributors; 2004.

8. Embil K, Nacht $\mathrm{S}$. The microsponge ${ }^{\circledR}$ delivery system (MDS): a topical delivery system with reduced irritancy incorporating multiple triggering mechanisms for the release of actives. J Microencapsul 1996;13:575-88.

9. Saraf A, Dasani A, Pathan H. Microsponge drug delivery system as an innovation in the cosmetic world: a review. Asian J Pharm Edu Res 2012;1:67-87.

10. Kumar S, Tyagi L, Singh D. Microsponge delivery system (MDS): A unique technology for delivery of active ingredients. Int J Pharm Sci Res 2011;2:3069-80.

11. Ibraheem D, Iqbal M, Agusti G, Fessi H, Elaissari A. Effects of process parameters on the colloidal properties of polycaprolactone microparticles prepared by double emulsion like process. Colloids Surf A Physicochem Eng Asp 2014;445:79-91.

12. Maravajhala V, Dasari N, Sepuri A, Joginapalli S. Design and evaluation of niacin microspheres. Indian J Pharm Sci 2009;71:663-9.

13. Nokhodchi A, Jelvehgari M, Siahi MR, Mozafari MR. Factors affecting the morphology of benzoyl peroxide microsponges. Micron 2007;38:834-40.

14. Qi F, Wu J, Fan Q, He F, Tian G, Yang T, et al. Preparation of uniform-sized exenatide-loaded PLGA microspheres as longeffective release system with high encapsulation efficiency and bio-stability. Colloids Surf B 2013;112:492-8.

15. Rizkalla CMZ, latif Aziz R, Soliman II. In vitro and in vivo evaluation of hydroxyzine hydrochloride microsponges for topical delivery. AAPS PharmSciTech 2011;12:989-1001.

16. Abdelmalak NS, El-Menshawe SF. A new topical fluconazole microsponge loaded hydrogel: preparation and characterization. Int J Pharm Pharm Sci 2012;4:460-9.

17. Luca G, Basta G, Calafiore R, Rossi C, Giovagnoli S, Esposito E, et al. Multifunctional microcapsules for pancreatic islet cell entrapment: design, preparation and in vitro characterization. Biomater 2003;24:3101-4.

18. Jain V, Jain D, Singh R. Factors effecting the morphology of eudragit S-100 based microsponges bearing dicyclomine for colonic delivery. J Pharm Sci 2011;100:1545-52.

19. Kavita, Kumar D, Singh K, Kumar S, Bhatti HS. Photoluminescent properties of SPAN-80 coated intrinsic and extrinsic $\mathrm{ZnO}$ nanostructures. Phys E (Amsterdam, Neth) 2016;79:188-97.

20. Jeffery H, Davis SS, O'Hagan DT. The preparation and characterization of poly (lactide-co-glycolide) microparticles. 
II. The entrapment of a model protein using a (water-in-oil)-inwater emulsion solvent evaporation technique. Pharm Res 1993;10:362-8.

21. Carrio A, Schwach G, Coudane J, Vert M. Preparation and degradation of surfactant-free PLAGA microspheres. J Controlled Release 1995;37:113-21.

22. Yang YY, Chung TS, Ng NP. Morphology, drug distribution, and in vitro release profiles of biodegradable polymeric microspheres containing protein fabricated by doubleemulsion solvent extraction/evaporation method. Biomater 2001;22:231-41.

23. Giri TK, Choudhary C, Ajazuddin, Alexander A, Badwaik H, Tripathi DK. Prospects of pharmaceuticals and biopharmaceuticals loaded microparticles prepared by double emulsion technique for controlled delivery. Saudi Pharm J 2013;21:125-41.

24. Marquette S, Peerboom C, Yates A, Denis L, Goole J, Amighi K. Encapsulation of immunoglobulin $\mathrm{G}$ by solid-in-oil-in-water: Effect of process parameters on microsphere properties. Eur J Pharm Biopharm 2014;86:393-403.

25. Kaity S, Maiti S, Ghosh A, Pal D, Ghosh A, Banerjee S. Microsponges: a novel strategy for drug delivery system. J Adv Pharm Technol Res 2010;1:283-90.

26. Morita T, Sakamura Y, Horikiri Y, Suzuki T, Yoshino H. Protein encapsulation into biodegradable microspheres by a novel S/O/W emulsion method using poly(ethylene glycol) as a protein micronization adjuvant. J Controlled Release 2000;69:435-44.

27. Abbas S, Da Wei C, Hayat K, Xiaoming Z. Ascorbic acid: microencapsulation techniques and trends-a review. Food Rev Int 2012;28:343-74.

28. Panicker CY, Varghese HT, Philip D. FT-IR, FT-raman and SERS spectra of vitamin C. Spectrochim Acta Part A 2006;65:802-4.

29. Zhang $\mathrm{H}, \mathrm{Xu} \mathrm{ZT}$, Li WQ, Yang SS. editors. Determination of vitamin $\mathrm{C}$ by infrared spectroscopy based on nonlinear modelling. Adv Mater Res 2011;236-238:2482-6.

30. Heidari A. Measurement the amount of vitamin $\mathrm{D}_{2}$ (Ergocalciferol), Vitamin $\mathrm{D}_{3}$ (Cholecalciferol) and absorbable Calcium $\left(\mathrm{Ca}^{2+}\right)$, Iron (II) $\left(\mathrm{Fe}^{2+}\right)$, Magnesium $\left(\mathrm{Mg}^{2+}\right)$, Phosphate $\left(\mathrm{PO}^{4-}\right)$ and Zinc $\left(\mathrm{Zn}^{2+}\right)$ in apricot using high-performance liquid chromatography (HPLC) and spectroscopic techniques. J Biom Biostat 2016;7:1-3.

\section{How to cite this article}

- $\quad$ Rabia Zia, Akmal Nazir, Muhammad Kashif Iqbal Khan, Abid Aslam Maan, Ayesha Rashid. Preparation of ascorbic acid and cholecalciferol microsponges for topical application. Int J Pharm Pharm Sci 2017;9(10):280-287. 